\title{
Uniform Square Polycrystalline Silicon Fabricated by Employing Periodic Metallic Pads and SiON Absorption Layer for Thin Film Transistors
}

\author{
Po-Chuan Yang, Chun-Yuan Hsueh, Chieh-Hung Yang, Jeng-Han Lee, Hui-Wen Lin, \\ Hsu-Yu Chang, Chi-Yang Chang, and Si-Chen Lee, Fellow, IEEE
}

\begin{abstract}
The polycrystalline silicon with regular square grains is fabricated by employing metallic $(\mathrm{Cr} / \mathrm{Al})$ periodic pads as the heat sinks and with underlying silicon oxynitride ( $\mathrm{SiON}$ ) as the heat absorption layer. The maximum lateral growth length of the poly-Si is $1.78 \mu \mathrm{m}$ by this method. If the metal pads are periodically arranged, the poly-Si can grow to regular square grains following the high power excimer laser annealing. After removing the metallic pads, the low power laser shot transfers the a-Si:H under the original metallic pads to poly-Si without destroying the square grains. The TFTs fabricated by this method achieve a field effect mobility of $450 \mathrm{~cm}^{2} / \mathrm{V} \cdot \mathrm{s}$ and an on/off current ratio exceeding $10^{7}$. It is found that the TFT with smaller channel width and length results in a better subthreshold swing because it contains fewer grain boundaries and defects.
\end{abstract}

Index Terms-Polycrystalline silicon, thin film transistor (TFT).

\section{INTRODUCTION}

$\mathbf{L}$ OW TEMPERATURE poly-Si thin film transistors (TFTs) fabricated by excimer laser annealing (ELA) have been widely applied in active matrix liquid crystal displays [1] and active matrix organic light emitting diodes [2], [3]. However, due to the fluctuation of pulse to pulse laser energy density and the thickness of the silicon film, it is difficult to control the uniformity of the poly-Si film. The important issue about uniformity is the grain size distribution in the channel region. If the grain size is regular and large, the grain boundaries in the channel can be fixed, and then, the uniformity and mobility of TFT can be improved. Several methods have been reported to improve the uniformity of the poly-Si film such as sequential lateral solidification [4], optical phase shift mask [5], grains controlled by floating structure [6], location control Si grain [7], $\mu$-Czochralski method [8], and excimer laser irradiation with a-Si spacers [9].

We have already reported one laser shot hexagonal grain poly-Si fabricated by employing metallic periodic pads and

Manuscript received November 14, 2007; revised March 13, 2008. This work was supported by the National Science Council of the Republic of China under Contract NSC 95-2221-E-002-298. The review of this paper was arranged by Editor H. Jaouen.

P.-C. Yang, C.-Y. Hsueh, C.-H. Yang, J.-H. Lee, H.-W. Lin, H.-Y. Chang, and C.-Y. Chang are with the Graduate Institute of Electronics Engineering, National Taiwan University, Taipei 10617, Taiwan, R.O.C.

S.-C. Lee is with the Department of Electrical Engineering and the Graduate Institute of Electronics Engineering, National Taiwan University, Taipei 10617, Taiwan, R.O.C. (e-mail: sclee@cc.ee.ntu.edu.tw).

Color versions of one or more of the figures in this paper are available online at http://ieeexplore.iee.org.

Digital Object Identifier 10.1109/TED.2008.925921

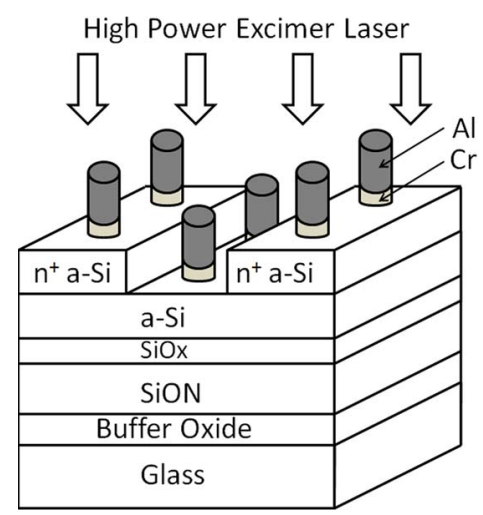

(a)

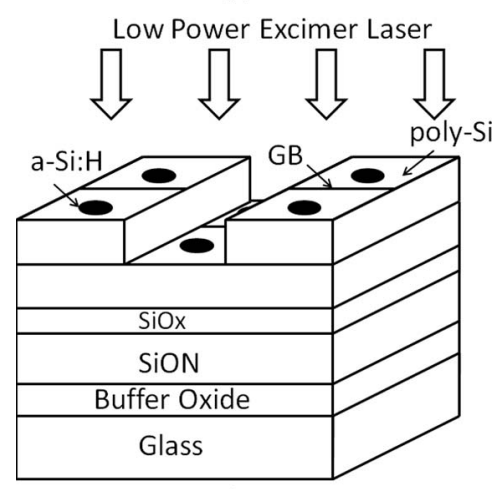

(b)

Fig. 1. Schematic diagram of regular square grain poly-Si by ELA with periodic $\mathrm{Cr} / \mathrm{Al}$ pads and $\mathrm{SiON}$ absorption layer. (a) High power excimer laser is applied to create square grain poly-Si. (b) After removing the metallic pads, the low power excimer laser crystallizes the a-Si region.

with underlying SiON heat absorption layer [10]. However, the amorphous central region in the active layer may affect the electrical performance of the poly-Si TFTs. Consequently, in this paper, after the first (high power) laser shot and removal of the metallic pads, the second (low power) laser shot transfers the a-Si:H region under the metallic pads to poly-Si. The scanning electron microscopy (SEM), atomic force microscopy (AFM), and transmission electron microscopy (TEM) are used to examine the large area uniformity, surface topography, and crystallization quality of the proposed poly-Si. The poly-Si TFTs fabricated by this method exhibit much better electrical performance than those fabricated by the same device structure with single high power laser irradiation and conventional poly-Si. 


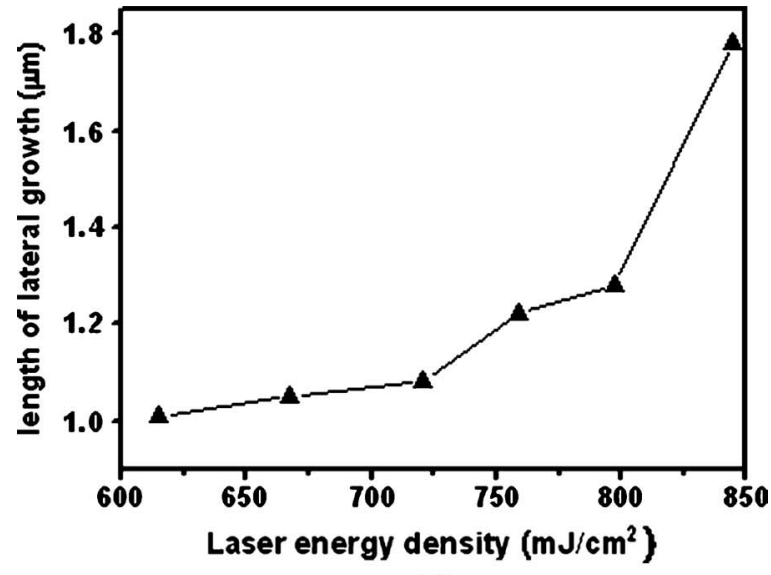

(a)

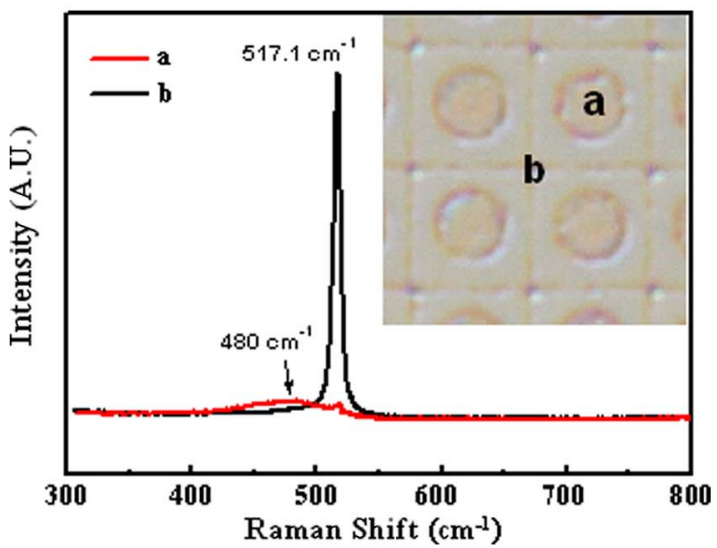

(b)

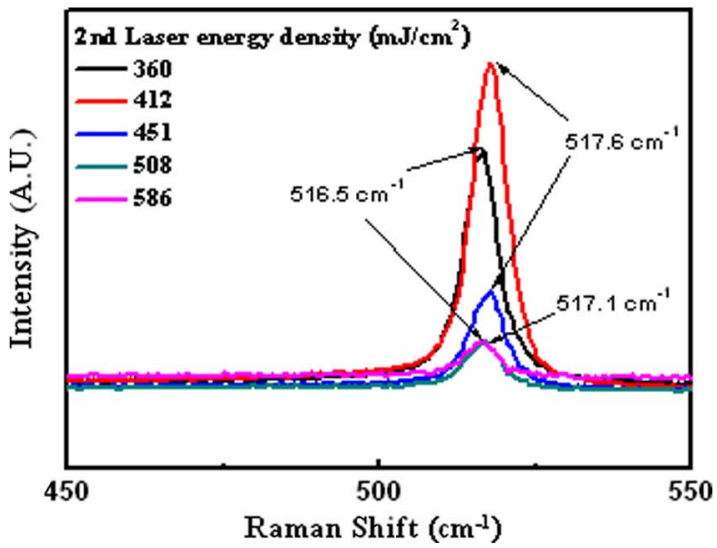

(c)

Fig. 2. (a) Variation of the lateral poly-Si growth length with the laser energy density. (b) Raman spectra of poly-Si film after the first laser shot $\left(840 \mathrm{~mJ} / \mathrm{cm}^{2}\right)$ at two different locations. (c) Raman spectra of poly-Si film after irradiating different low power laser energy densities.

\section{EXPERIMENTS}

Fig. 1 shows the schematic diagram of this process. First, a 385-nm-thick SiON layer is grown as a heat absorption layer by plasma enhanced chemical vapor deposition (PECVD) on the $1737 \mathrm{~F}$ glass substrate with buffered oxide. Then, 5-nm-thick silicon oxide $\left(\mathrm{SiO}_{x}\right)$ is deposited as the insulating layer. Moreover, 50-nm-thick a-Si:H and 20-nm-thick n-type phosphorus-doped a-Si:H layers are deposited by PECVD on the $\mathrm{SiO}_{x}$. During deposition, the substrate temperature, RF

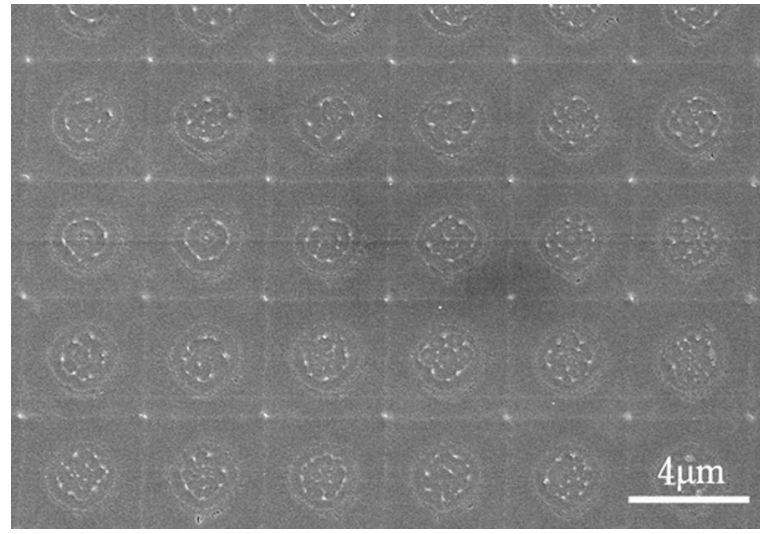

Fig. 3. SEM image of square grain poly-Si film after two excimer laser shots and Secco etching.

power density, and chamber pressure are fixed at $250{ }^{\circ} \mathrm{C}$, $0.11 \mathrm{~W} / \mathrm{cm}^{2}$, and 0.45 torr, respectively. Third, the n-type a-Si:H layer is patterned and etched by reactive ion etching (RIE) to define the channel region of the TFT. After that, the sample is sent to furnace to dehydrogenate for $10 \mathrm{~min}$ at $500{ }^{\circ} \mathrm{C}$ under nitrogen environment. Then, the patterned round metal $(\mathrm{Cr} / \mathrm{Al}, 25 / 700 \mathrm{~nm})$ pads arranged in a square lattice are deposited on top of the silicon film, as shown in Fig. 1(a). The purpose of the $\mathrm{Al}$ metallic pads is to reflect the laser light and the $\mathrm{Cr}$ layer under $\mathrm{Al}$ metallic pads is to impede the $\mathrm{Al}$ diffusion into Si layer during ELA [9]. Next, the film is irradiated by high power excimer laser $(\mathrm{KrF}$, pulse duration time of $28 \mathrm{~ns}$, $840 \mathrm{~mJ} / \mathrm{cm}^{2}$ ) at room temperature, and the amorphous silicon region without metallic pads will be melted. Because the metallic pads reflect most laser, the metallic pads will be cooler than the melted amorphous region. The nucleated silicon crystals grow radially from the edge of unmelted amorphous region (heat sink) and collide with others at the middle of two metallic pads to form the regular poly-Si grain. Then, the metallic $(\mathrm{Cr} / \mathrm{Al})$ pads are removed by etching solution. The low power laser $\left(410 \mathrm{~mJ} / \mathrm{cm}^{2}\right)$ is applied to crystallize the original amorphous region under the metal pads, as shown in Fig. 1(b), without destroying the square grain formed by high power laser annealing [10]. Moreover, the square grains beyond the metal pads which are crystallized by the first laser shot are also postannealed by the second laser shot; therefore, their quality are improved. Next, the sample is mesa etched by RIE to define the device region and channel width. Finally, after depositing 150 -nm oxide as the gate insulator and pattering the gate metal, the TFT is completed.

\section{RESUlTS AND Discussion}

Fig. 2(a) shows the lateral growth length of poly-Si as a function of excimer laser energy density for the proposed structure fabricated by utilizing metallic pads as heat sinks and $\mathrm{SiON}$ layer as heat absorption layer. The maximum lateral growth length is $1.78 \mu \mathrm{m}$ when the irradiating laser energy density reaches $840 \mathrm{~mJ} / \mathrm{cm}^{2}$, which is the highest density that can be achieved by our KrF excimer laser system. Fig. 2(b) shows the Raman spectra of the poly-Si film after the first laser shot $\left(840 \mathrm{~mJ} / \mathrm{cm}^{2}\right)$ at two different locations. The central 


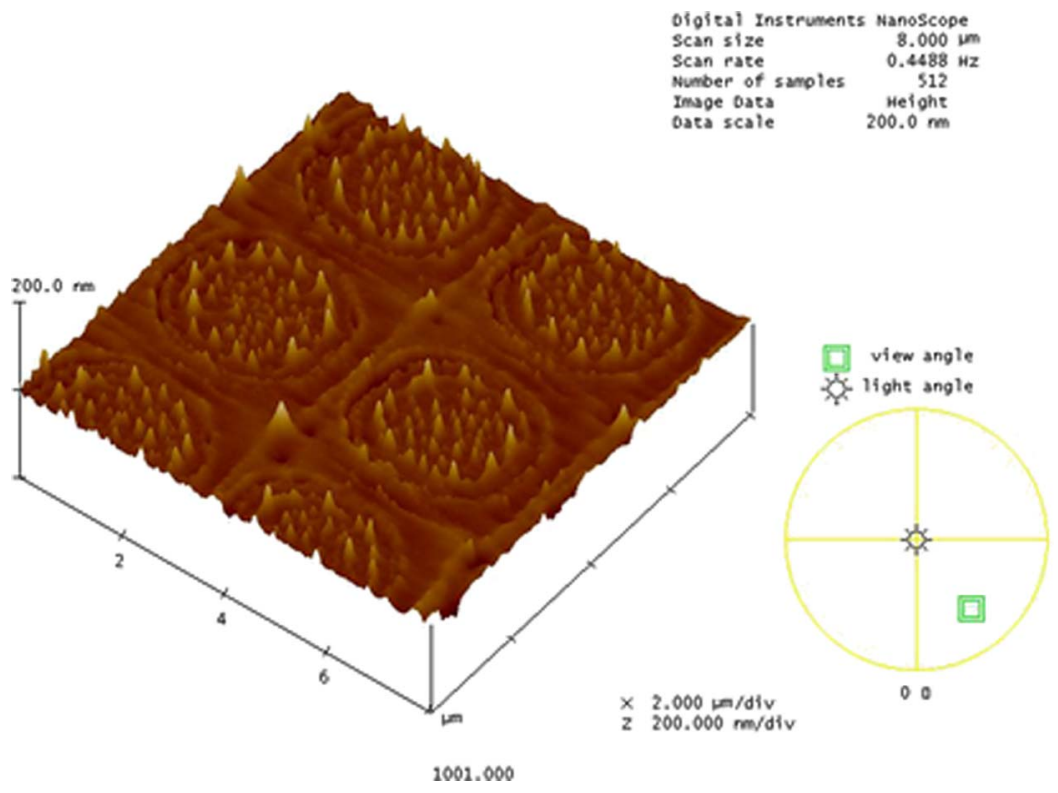

Fig. 4. AFM image of the square grain poly-Si film after a high power plus low power laser irradiation.

round area (point a) is the silicon film after the first laser shot and striping off of the top metal pads. The Raman spectra shows a broad peak at $480 \mathrm{~cm}^{-1}$, indicating an amorphous silicon. The Raman peak of the poly-Si region (point b) exhibits a sharp peak at $517.1 \mathrm{~cm}^{-1}$, which is a characteristic of crystalline silicon. The reason for using lower laser fluence $\left(410 \mathrm{~mJ} / \mathrm{cm}^{2}\right)$ for second pulse is shown in the Raman spectra of poly-Si, as shown Fig. 2(c). The poly-Si film shows the best crystallinity when the second laser shot energy density is $410 \mathrm{~mJ} / \mathrm{cm}^{2}$.

Fig. 3 shows the SEM image of the proposed poly-Si film after two laser shots with regular square grains after Secco etching (radius of the metallic pad $=1.08 \mu \mathrm{m}$, distance between two pads $=4 \mu \mathrm{m})$. The regular grains with very clear boundaries are observed. This proves that the proposed technique can create very uniform and regular square-shaped poly-Si grains. Fig. 4 shows the AFM images of square lattice poly-Si after two laser shots. After laser crystallization, the neighboring four grains collide to produce protrusions at the corners of the square grains [11]. The average height of the protrusions are $45 \mathrm{~nm}$.

TEM is used to analyze the quality of poly-Si grains. Fig. 5(a) and (b) show the bright- and dark-field views of the square grain, respectively. The diffraction patterns of central polySi region under the metal pads (point $\mathrm{A}$ ) and exposed region (point B) after two laser shots are shown in Fig. 5(a). It is clear that the square grains contain subgrains in radial direction because the grains nucleate from the edge of the metallic pads following higher power laser shots. Moreover, through the diffraction pattern in Fig. 5(a), the poly-Si grains at point $\mathrm{A}$ are randomly distributed and the grain size is smaller than that at point $\mathrm{B}$. The grains at point $\mathrm{B}$ are oriented along [631] direction.

Fig. 6 shows the location of the regular square grains inside the TFT channel with different channel width to length ratios $(W / L=5 / 5,4 / 4$, and $4 / 2 \mu \mathrm{m} / \mu \mathrm{m})$. The grain boundaries and central circular regions are observed clearly. Fig. 7 shows the

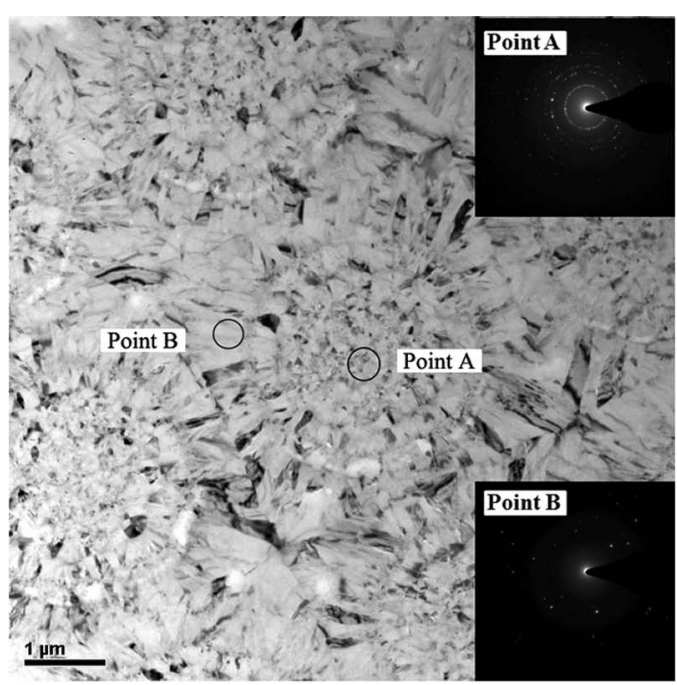

(a)

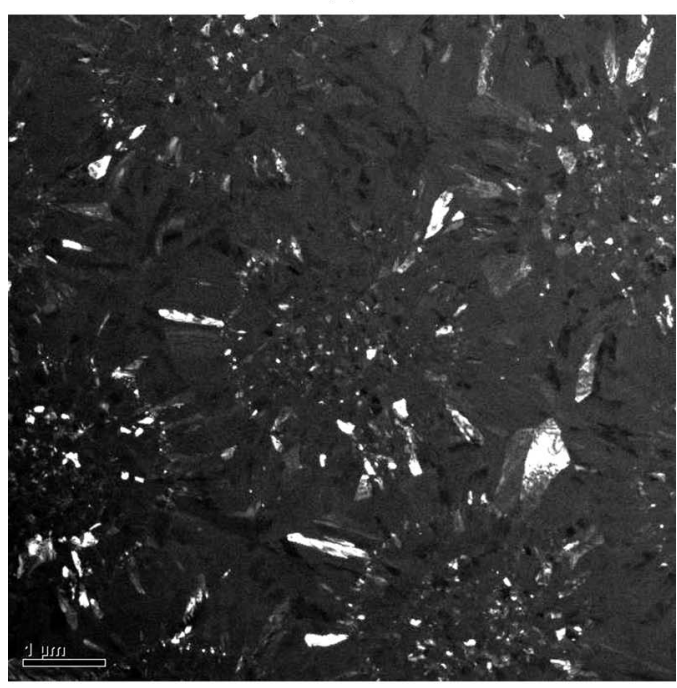

(b)

Fig. 5. TEM image of (a) bright-field view and (b) dark-field view of a square poly-Si grain after two laser shots. 


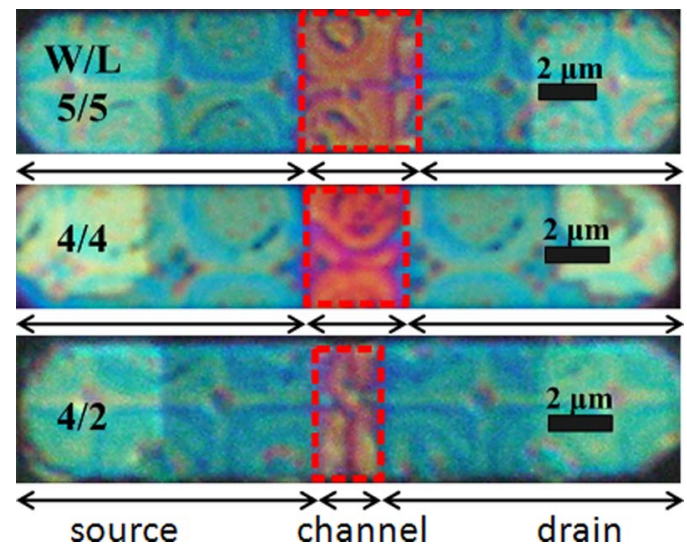

Fig. 6. OM images of the channels of the TFTs made by two laser shots with the square poly-Si grain inside. $(W / L=5 / 5,4 / 4$, and $4 / 2 \mu \mathrm{m} / \mu \mathrm{m})$. The arrows indicate the source, channel, and drain regions of three poly-Si TFTs.

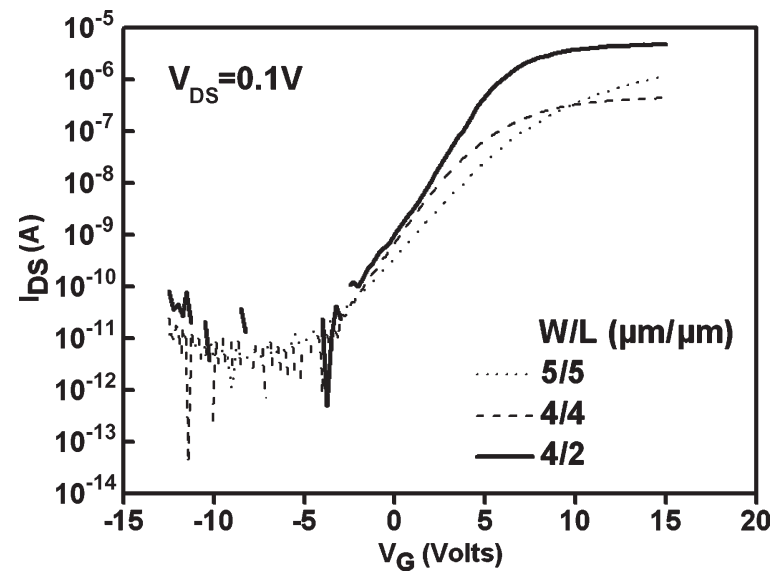

Fig. 7. Transfer curves of poly-Si TFTs with regular square poly-Si grain with different width to length ratios $(W / L=5 / 5,4 / 4$, and $4 / 2 \mu \mathrm{m} / \mu \mathrm{m})$.

TABLE I

COMPARISON OF REgUlar SQUARE POLY-Si TFT PERFORMANCE With DifFERENT $W / L$ RATIOS

\begin{tabular}{cccc}
\hline $\begin{array}{c}\mathrm{W} / \mathrm{L} \\
(\mu \mathrm{m} / \mu \mathrm{m})\end{array}$ & $\begin{array}{c}\text { On/ Off } \\
\mathrm{V}_{\mathrm{D}}=0.1 \mathrm{~V}\end{array}$ & $\begin{array}{c}\text { Mobility } \\
\left(\mathrm{cm}^{2} / \mathrm{V} \text {-sec }\right)\end{array}$ & $\begin{array}{c}\mathrm{V}_{\mathrm{T}} \\
(\mathrm{V})\end{array}$ \\
\hline $5 / 5$ & $10^{6}$ & 233 & 5.4 \\
\hline $4 / 4$ & $10^{7}$ & 348 & 6.2 \\
\hline $4 / 2$ & $10^{7}$ & 450 & 3.4 \\
\hline
\end{tabular}

transfer curves of TFTs made by the two-laser-shot method with different $W / L$ ratios. From the figure, the TFT with the smaller channel width and length $(4 / 2 \mu \mathrm{m} / \mu \mathrm{m})$ results in the smallest subthreshold swing, which is $\sim 0.4 \mathrm{~V} /$ decade at $V_{G}=$ $-3.5 \mathrm{~V}$ because it contains fewer grain boundaries and, thus, fewer defects. It is generally believed that the grain boundary acts as a trapping center which degrades the performance of the TFTs. Table I lists the comparison of these three TFTs with different $W / L$ ratios $(W / L=5 / 5,4 / 4$, and $4 / 2 \mu \mathrm{m} / \mu \mathrm{m})$. The mobility of the TFT with $W / L=4 / 2$ is $450 \mathrm{~cm}^{2} / \mathrm{V} \cdot \mathrm{s}$, and the threshold voltage $\left(V_{T}\right)$ is $3.4 \mathrm{~V}$.

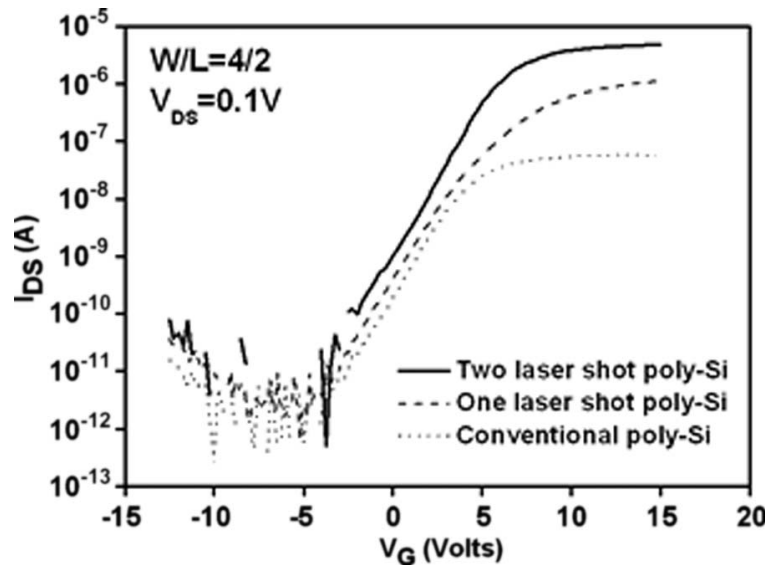

Fig. 8. Comparison of transfer curves of TFTs made by two laser shots, a single high power laser shot, and the conventional ELA poly-Si.

TABLE II

COMPARISON OF TFT PERFORMANCE $(W / L=4 / 2 \mu \mathrm{m} / \mu \mathrm{m})$ USING DIFFERENT TECHNOLOGIES

\begin{tabular}{cccc}
\hline Poly-Si & $\begin{array}{c}\text { On/ Off } \\
\mathrm{V}_{\mathrm{D}}=0.1 \mathrm{~V}\end{array}$ & $\begin{array}{c}\text { Mobility } \\
\left(\mathrm{cm}^{2} / \mathrm{V}-\mathrm{sec}\right)\end{array}$ & $\begin{array}{c}\mathrm{V}_{\text {th }} \\
(\mathrm{V})\end{array}$ \\
\hline Two laser shot & $10^{7}$ & 450 & 3.4 \\
\hline $\begin{array}{c}\text { Single high power } \\
\text { laser shot }\end{array}$ & $10^{6}$ & 250 & 6.3 \\
\hline Conventional & $10^{5}$ & 15 & 7.6 \\
\hline
\end{tabular}

Fig. 8 shows the transfer curves of three poly-Si TFTs made with 1) two laser shots, 2) a single high power laser shot leaving amorphous silicon in the central circular region, and 3) the conventional method by direct ELA. It is clear that the proposed poly-Si TFT with regular square grain exhibits the best subthreshold swing, which is $\sim 0.4 \mathrm{~V} /$ decade at $V_{G}=$ $-3.5 \mathrm{~V}$, and on/off current ratio of $10^{7}$. Table II lists the comparison of these three TFTs. The poly-Si TFT with two laser shots exhibits the best electrical properties; the mobility of $450 \mathrm{~cm}^{2} / \mathrm{V} \cdot \mathrm{s}$ is almost twice as high as that with a single high power laser shot $\left(250 \mathrm{~cm}^{2} / \mathrm{V} \cdot \mathrm{s}\right)$ and 30 times larger than that with conventional poly-Si $\left(15 \mathrm{~cm}^{2} / \mathrm{V} \cdot \mathrm{s}\right)$. Otherwise, the $V_{\text {th }}$ of the TFT with two-laser-shot regular grain is the smallest (3.4 V) among these three TFTs. It proves that this two laser shot process can significantly improve the device performance.

Fig. 9(a) and (b) show the statistics of the percentage variations of the threshold voltage $\left(\left(V_{T}-V_{\text {Tave }}\right) / \mathrm{V}_{\text {Tave }}\right) \times$ $100 \%$ and mobility $\left(\left(\mu-\mu_{\text {ave }}\right) / \mu_{\text {ave }}\right) \times 100 \%$ for poly-Si TFTs fabricated by three different technologies with $W / L=$ $4 / 2 \mu \mathrm{m} / \mu \mathrm{m}$. The percentage variations of the threshold voltage of three poly-Si TFTs with two laser shots, a single high power laser shot, and the conventional method by direct ELA are $+16 \%--9 \%,+19 \%--11 \%$, and $+53 \%--47 \%$, respectively. Moreover, the percentage variations of the mobility of three poly-Si TFTs with two laser shots, a single high power laser shot, and the conventional method by direct ELA are $+15 \%--7 \%,+13 \%--16 \%$, and $+83.8 \%--85.7 \%$, respectively. It indicates that the uniformity of the electrical performance improves substantially by this process. 


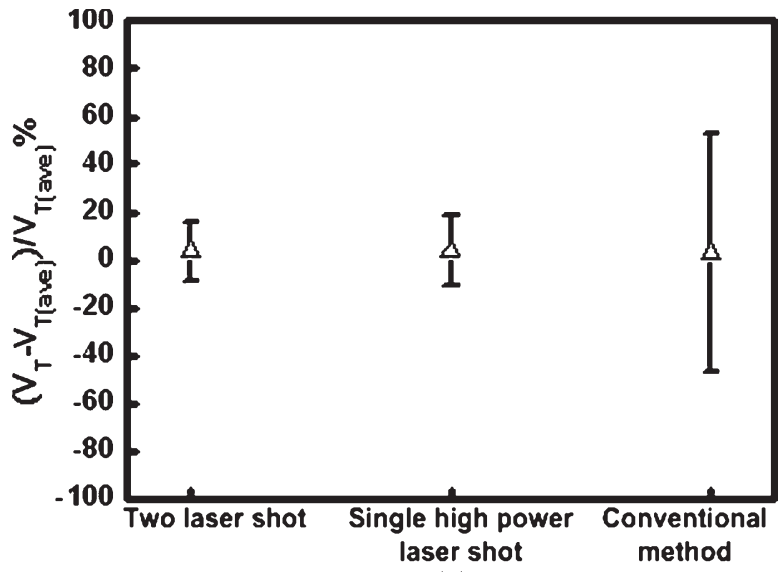

(a)

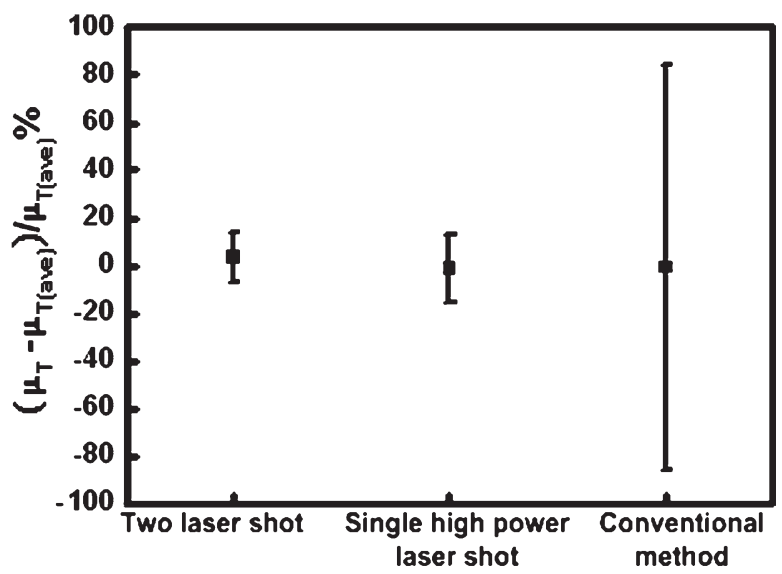

(b)

[5] C. H. Oh and M. Matsumura, "A proposed single grain-boundary thinfilm transistor," IEEE Electron Device Lett., vol. 22, no. 1, pp. 20-22, Jan. 2001.

[6] I. H. Song, S. H. Kang, W. J. Nam, and M. K. Han, "A high-performance multichannel dual-gate poly-Si TFT fabricated by excimer laser irradiation on a floating a-Si thin film," IEEE Electron Device Lett., vol. 24, no. 9, pp. 580-582, Sep. 2003.

[7] H. Kumomi, C. Shin, G. Nakagawa, and T. Asano, "Single-grain TFTs on location controlled crystal grains formed by excimer laser crystallization of Si thin films," in IEDM Tech. Dig., Dec. 13-15, 2004, pp. 773-776.

[8] R. Vikas, R. Ishihara, Y. Hiroshima, D. Abe, S. Inoue, T. Shimoda, W. Metselaar, and K. Beenakker, "Capping layer on thin Si film for $\mu$-Czochralski process with excimer laser crystallization," Jpn. J. Appl. Phys., vol. 45, no. 5B, pp. 4340-4343, 2006.

[9] H.-C. Cheng, C.-C. Tsai, J.-H. Lu, H.-H. Chen, B.-T. Chen, T.-K. Chang, and C.-W. Lin, "Periodically lateral silicon grains fabricated by excimer laser irradiation with a-Si spacers for LTPS TFTs," J. Electrochem. Soc., vol. 154, no. 1, pp. J5-J10, 2007.

[10] T. Mizuki, J. Shibata Matsuda, Y. Nakamura, J. Takagi, and T. Yoshida, "Large domains of continuous grain silicon on glass substrate for highperformance TFTs," IEEE Trans. Electron Devices, vol. 51, no. 2, pp. 204-211, Feb. 2004.

[11] H. Y. Chang, C. Y. Meng, M. W. Tsai, B. C. Yang, T. H. Chuang, and S. C. Lee, "The improvement of polycrystalline silicon TFTs fabricated by employing periodic metal pads," IEEE Trans. Electron Devices, vol. 53, no. 8, pp. 1939-1943, Aug. 2006.

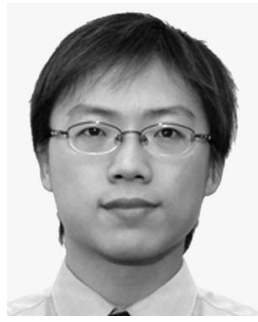

Po-Chuan Yang was born in Taiwan, R.O.C., on January 3, 1981. He received the B.S. degree in mechanical engineering from National Taiwan University, Taipei, Taiwan, in 2003.

$\mathrm{He}$ is currently with the Graduate Institute of Electronics Engineering, National Taiwan University. His research interests are low temperature polysilicon thin film transistors and flexible electronics.

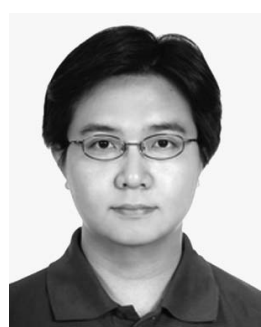

Chun-Yuan Hsueh was born in Taiwan, R.O.C., on June 8, 1982. He received the B.S. and M.S. degrees in electrical engineering both from National Taiwan University, Taipei, Taiwan, in 2004 and 2006, respectively.

He is currently with the Graduate Institute of Electronics Engineering, National Taiwan University. His research interest is low temperature polysilicon thin film transistors.

fabricated successfully by employing periodic metallic $(\mathrm{Cr} / \mathrm{Al})$ pads and SiON heat absorption layer. The TFT with width to length ratio of $W / L=4 / 2 \mu \mathrm{m} / \mu \mathrm{m}$ exhibits the best performance, i.e., an on/off current ratio exceeding $10^{7}$, mobility of $450 \mathrm{~cm}^{2} / \mathrm{V} \cdot \mathrm{s}$, and substantially improved uniformity in electrical performance, which is much better than those of the poly-Si TFTs fabricated by using a single high power laser shot or the conventional poly-Si prepared by direct ELA.

\section{REFERENCES}

[1] J. W. Park, M. C. Lee, W. J. Nam, I. H. Song, and M. K. Han, "A polySi TFT integrated gate-data line-crossover structure employing an air-gap for large-size AMLCD panel," IEEE Electron Device Lett., vol. 22, no. 8, pp. 402-404, Aug. 2001.

[2] C. C. Wu, S. D. Theiss, G. Gu, M. H. Lu, J. C. Sturm, S. Wagner, and S. R. Forrest, "Integration of organic LEDs and amorphous Si TFTs onto flexible and lightweight metal foil substrates," IEEE Electron Device Lett., vol. 18, no. 12, pp. 609-612, Dec. 1997.

[3] J. Y. Lee, J. H. Kwon, and H. K. Chung, "High efficiency and low power consumption in active matrix organic light emitting diode," Organic Electron., vol. 4, no. 2/3, pp. 143-148, Sep. 2003.

[4] M. A. Crowder, P. G. Carey, P. M. Smith, R. S. Sposili, H. S. Cho, and J. S. Im, "Low-temperature single-crystal Si TFTs fabricated on Si films processed via sequential lateral solidification," IEEE Electron Device Lett., vol. 19, no. 8, pp. 306-308, Aug. 1998.

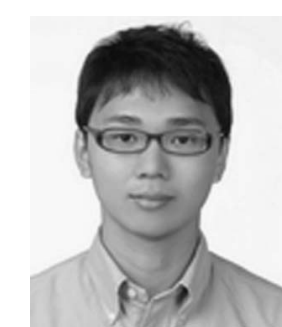

Chieh-Hung Yang was born in Taiwan, R.O.C., on April 26, 1982. He received the B.S. degree in electrical engineering from National Taiwan University, Taipei, Taiwan, in 2004.

$\mathrm{He}$ is currently with the Graduate Institute of Electronics Engineering, National Taiwan University. His research interest is microcrystalline silicon solar cells.

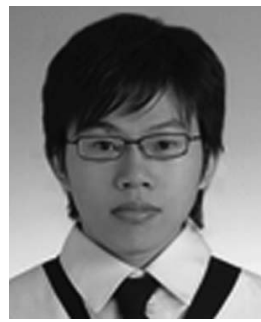

Jheng-Han Lee was born in Taiwan, R.O.C., on October 29, 1984. He received the B.C. degree in materials science and engineering from National Tsing Hua University, Hsinchu, Taiwan, in 2006.

$\mathrm{He}$ is currently with the Graduate Institute of Electronics Engineering, National Taiwan University, Taipei, Taiwan. His research interests are $\mathrm{Si}$ processes and quantum dot quantum ring photodetectors. 


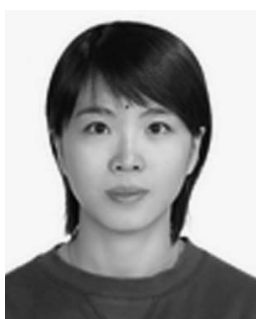

Hui-Wen Lin was born in Taiwan, R.O.C., on September 14, 1984. She received the B.C. degree in materials science and engineering from National Tsing Hua University, Hsinchu, Taiwan, in 2006.

She is currently with the Graduate Institute of Electronics Engineering, National Taiwan University, Taipei, Taiwan. Her research interest is amorphous silicon solar cells with high open-circuit voltage.

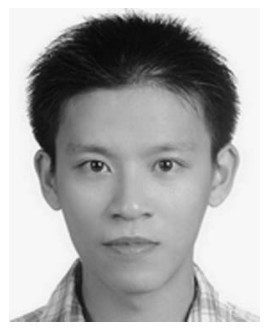

Hsu-Yu Chang was born in Taiwan, R.O.C., on November 12, 1981. He received the B.C. degree in materials science and engineering from $\mathrm{Na}-$ tional Tsing Hua University, Hsinchu, Taiwan, in 2003 and the M.S. degree in electrical engineering from National Taiwan University, Taipei, Taiwan, in 2005 .

$\mathrm{He}$ is currently with the Graduate Institute of Electronics Engineering, National Taiwan University. His research interest is active-matrix organic light emitting diodes with passivation.

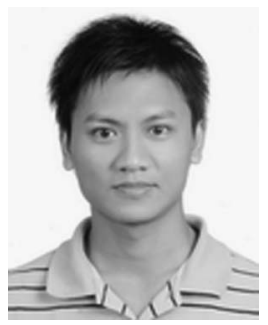

Chi-Yang Chang was born in Taiwan, R.O.C., on March 16, 1983. He received the B.C. degree in electrical engineering from National Tsing Hua University, Hsinchu, Taiwan, in 2005 and the M.S. degree in electrical engineering from National Taiwan University, Taipei, Taiwan, in 2005.

$\mathrm{He}$ is currently with the Graduate Institute of Electronics Engineering, National Taiwan University. His research interests are the device and physics of quantum dot (InAs/GaAs) surface plasmon.

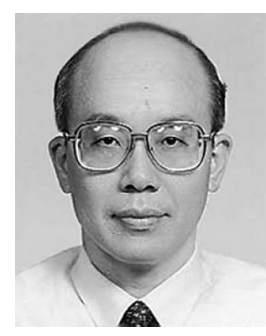

Si-Chen Lee (A'84-SM'90-F'02) was born in Taiwan, R.O.C., on August 13, 1952. He received the B.S. degree in electrical engineering from $\mathrm{Na}-$ tional Taiwan University, Taipei, Taiwan, in 1974 and the Ph.D. degree in electrical engineering from Stanford University, Stanford, CA, in 1981 with a work consisting of the experimental investigation of the $\mathrm{AlGaAs} / \mathrm{GaAs}$ multiheterojunction properties.

From 1980 to 1982, he was with Energy Conversion Devices Inc., Troy, MI, where he was concerned with the application of amorphous silicon hydrogen alloy to solar cells. He has been with the Department of Electrical Engineering, National Taiwan University since 1982 as a Visiting Associate Professor and, currently, as a Professor. He was the Chairman of the department from 1988 to 1992 and the Dean of academic affairs of National Taiwan University from 1996 to 2002. He is also with the Graduate Institute of Electronics Engineering, National Taiwan University. He has been the President of National Taiwan University since June 2005. His current research interests are in the device applications and growth kinetics of InGaAs/GaAs strained layer quantum dot devices, InGaAs/InAs room temperature infrared light emitting diodes, and photodetectors with applications to the pollution detection and biological reaction of cells. In addition, he is also interested in hydrogenated and deuterated amorphous and polysilicon (carbon, germanium) hydrogen materials and devices such as thin film transistors and neural network image sensors. Since 1988, he has been pioneering a research work on the Chinese traditional qigong and somatic science.

Dr. Lee is a member of the Chinese Institute of Electrical Engineering and the recipient of the Dr. Sun Yat-San Academic award in 1987 and five consecutive outstanding research awards of the National Science Council from 1986 to 1996 . He was elected as a member of the Asia-Pacific Academy of Materials in 1997 and was the recipient of the IEEE Third Millennium Medal for outstanding achievements and contributions in the area of semiconductor devices in 2000. In 2002, he was awarded the Medal of Electrical Engineering from the Association of Chinese Electrical Engineers. He was the recipient of the 47th Academic Award of the Ministry of Education in 2003. 